\title{
Quality of sleep and associated factors among people living with HIV/AIDS on follow up at Ethiopian Zewditu memorial hospital, 2018
}

\author{
Nebiyu Mengistu ${ }^{1}$, Telake Azale ${ }^{2}$, Solomon Yimer $^{1 *}$ (D, Mahlet Fikreyesus ${ }^{3}$, Elsa Melaku ${ }^{3}$ and Seid Shumye
}

\begin{abstract}
Background: Sleep disturbance is a common complaint in people living with HIV/AIDS. Despite the influence of sleep disturbance on treatment adherence, quality of life, work productivity, risk of chronic illness, it remains under-recognized and under-studied in Ethiopia. Therefore it is necessary to produce scientific evidence to fill the knowledge gap and areas of management. The current study aimed to assess sleep quality and its associated factors among people living with HIV/AIDS.

Methods: An institution-based cross-sectional study was utilized among 408 participants who were selected by a systematic random sampling technique at Zewditu memorial hospital from April to May 2018. The Pittsburgh Sleep Quality Index questionnaire was used to measure sleep quality. Ethical clearance was obtained from the joint ethics committee of the University of Gondar and Amanuel Mental Specialized Hospital. Oral informed consent was obtained from each participant. Binary and multivariable logistic regression models were fitted. Odds ratios (OR) with the corresponding 95\% confidence interval $(95 \% \mathrm{Cl})$ was computed.

Results: The magnitude of poor sleep quality was 55.6\%. Being female [AOR $=3.40,95 \% \mathrm{Cl}:(1.80,6.41)]$, depression $[A O R=3.52,95 \% \mathrm{Cl}:(1.95,6.32)], C D_{4}$ Count $\leq 200 \mathrm{cells} / \mathrm{mm}^{3}$ [AOR $\left.=3.18,95 \% \mathrm{Cl}:(1.65,6.13)\right]$, duration of HIV/AIDS diagnosis $[\mathrm{AOR}=3.43,95 \% \mathrm{Cl}:(1.61,7.29)]$, current use of tobacco $[\mathrm{AOR}=5.69,95 \% \mathrm{Cl}:(2.04,15.9)]$ and chat or caffeinated drinks $[A O R=2.65,95 \% \mathrm{Cl}:(1.06,6.64)]$ and poor sleep hygiene $[\mathrm{AOR}=3.55,95 \% \mathrm{Cl}:(1.85,6.78)]$ were significantly associated with poor sleep quality.

Conclusions: More than half of the study participants were found to have poor sleep quality. A range factors influence quality of sleep of people with HIV/AIDS. Routine screening of sleep condition among people living with HIV/AIDS and early intervention based on the findings is suggested.
\end{abstract}

Keywords: HIV/AIDS, Sleep habits, AIDS, Sleep hygiene, Prevalence studies

\section{Background}

Sleep is a natural process that the brain requires to keep proper functioning and maintain the health of the human body. Sleep occupies one third of human life and its deprivation causes negative consequences that may be physical, cognitive, or emotional. Suffering from inadequate

\footnotetext{
* Correspondence: sopsycha@gmail.com

'Department of Psychiatry, Dilla University, P.O.Box (DU): 419, Dilla, Ethiopia Full list of author information is available at the end of the article
}

sleep has been associated with chronic medical illness like diabetes, stroke, heart disease and Human immunodeficiency virus or Acquired immune deficiency syndrome (HIV/AIDS) (Barlow 2014; Association AP 2013).

HIV/AIDS is a chronic, potentially life threatening condition caused by the HIV, which affects mostly the immune system and nervous system. HIV/AIDS is among the most overwhelming health problems throughout the world and especially in developing countries (Johnston et al. 2017). An approximated 36.7

(c) The Author(s). 2021 Open Access This article is licensed under a Creative Commons Attribution 4.0 International License, which permits use, sharing, adaptation, distribution and reproduction in any medium or format, as long as you give

appropriate credit to the original author(s) and the source, provide a link to the Creative Commons licence, and indicate if changes were made. The images or other third party material in this article are included in the article's Creative Commons licence, unless indicated otherwise in a credit line to the material. If material is not included in the article's Creative Commons licence and your intended use is not permitted by statutory regulation or exceeds the permitted use, you will need to obtain permission directly from the copyright holder. To view a copy of this licence, visit http://creativecommons.org/licenses/by/4.0/ 
million people are living with HIV/AIDS in the world. In Ethiopia, the national adult HIV/AIDS prevalence has been reported to be $1.14 \%$. It has been estimated that 542,121 adults and 178,500 children require antiretroviral treatment in Ethiopia (Azagew et al. 2017). Sleep disturbance is one of the most prevalent symptoms in individuals infected with HIV/AIDS where 40 to $70 \%$ of individuals infected with HIV/AIDS are reporting significant sleep disturbances, including difficulty falling asleep, awakenings during the night, and reduced sleep time (Taibi 2013; Reid and Dwyer 2005; Rubinstein and Selwyn 1998).

Sleep disturbance among people living with HIV/AIDS occurs throughout the stages of the infection, but more prevalent in the advanced stage. Despite this fact, still the condition receives little attention (Junqueira et al. 2008). This may be, because sleep disturbance is considered as a normal consequence of the disease and its treatment, or considered to be insignificant in comparison with other complications of HIV infection (McGrath and Reid 2008).

But sleep deprivation among people living with HIV/ AIDS leads to various effects, such as impaired immune system, hampered physical performance, affected cell growth and repair, deteriorated neuronal connections and neuronal malfunctions (Qaseem et al. 2016). In addition, it may also increase the risk of cardiovascular morbidity and mortality, and the degree of suffering with psychiatric disorders (Gamaldo et al. 2013).

According to study results, sleep disturbance is not only prevalent, but also there are more intense and distressful symptoms experienced by the HIV population. As a result, such individuals are less likely to adhere to their antiretroviral therapy regimens probably as a result of depression (Reid and Dwyer 2005; Saberi et al. 2011; Babson et al. 2013; Hudson et al. 2004).

Cross-sectional surveys conducted in China and France showed that prevalence of sleep disturbances and Poor sleep quality was 43.1 and $47 \%$ respectively. Prevalence of sleep disturbances differed significantly between those who suffered anxiety and depression and those who did not. Moreover, being male, a smoker, living single, being unemployed or moderately or seriously depressed were significantly associated with poor sleep quality (Huang et al. 2017; Allavena et al. 2016).

According to a survey conducted in Latin America countries Mexico and South East Brazil 58.6 and 46.7\% had poor sleep quality respectively. Depressive symptoms, illicit drug use, a CD4 count $<200$ cells/ $\mu \mathrm{l}$, and longer duration of HIV/AIDS diagnosis was positively associated with poor sleep quality (Ferreira and Ceolim 2012; Rodríguez-Estrada et al. 2018a).

Similarly, studies conducted in Nigeria among HIVpositive outpatients reported that $46.2 \%$ in University of
Calabar Teaching Hospital and 59.3\% in Lagos State University Teaching Hospital had sleep disorders and poor sleep quality respectively. Elevated systolic blood pressure, shorter duration of HIV diagnosis and highly active antiretroviral therapy (HAART) type were associated with sleep disorders and poor sleep quality (Bisong 2017; Oshinaike et al. 2014).

Despite this significant health problems and higher prevalence, sleep quality among people with HIV/AIDS remains under-studied with no published study in Ethiopia. Beside that the current study addressed key correlated factors that could be managed by health care providers for better treatment outcome and control of psychological problems among people with HIV/AIDS. Therefore, the aim of this study was to assess the magnitude of sleep quality and its associated factors among people living with HIV/AIDS in Zewditu Memorial Hospital, Ethiopia.

\section{Methods \\ Study design, period, setting, and population}

An institutional-based cross-sectional study was conducted from April to May 2018 in Zewditu Memorial Hospital which is found in Addis Ababa, Ethiopia. Center for Disease Control and prevention (CDC-Ethiopia) helped the launch of Ethiopia's first antiretroviral therapy (ART) program at Zewditu Memorial Hospital in July 2003, and in March 2005. The program received technical assistance from Johns Hopkins University's TSEHAI Program. Zewditu Memorial Hospital became the largest HIV clinic in Ethiopia and a leading hospital in the treatment of antiretroviral therapy patients. Currently, the hospital treats over 7299 patients each month. There were 17,857 HIV-positive patients having HIV care follow-up in the hospital in 2018. The study population was patients who were attending at ART clinics during the data collection period. All adults who were seriously ill and unable to communicate were not included in the study.

\section{Sample size and sampling technique}

Sample size (n) was calculated based on single population proportion formula, by assuming 95\% confidence level, the prevalence of poor sleep quality among HIV/AIDS patients which was found to be $59.3 \%$ in Nigeria (Oshinaike et al. 2014) and a precision of $5 \%$ between the sample and the parameter was taken. $\alpha=0.05(95 \%)=1.96$.

By considering a $10 \%$ non-response rate the final sample size was 408 . We used a systematic sampling technique to select the four hundred eight (408) HIV/AIDS patients who were included in our survey. We determined the sampling interval by dividing the total study population who had to follow up during the average 1month data collection period (3264) by total sample size 
(408). Hence, the sample interval is eight. We selected the first study participant by lottery method and the next study participants were chosen every 8th interval for interview.

\section{Data collection tools and procedures}

Data were collected by trained nurses by face-to-face interviewing of the participant attending ART service using paper and pencil. The questionnaire was pretested by taking $5 \%$ of the calculated sample size and modified accordingly to easily understand by the study participants. The questionnaire contained sociodemographic characteristics (age, income, education, occupation, marital status, and others), questions to collect data on clinical factors and standard tools to address other independent variables of the study.

Data on the components of sleep quality was collected by using the Pittsburgh Sleep Quality Index (PSQI), a self-report measure instrument composed of 19 items evaluating seven components of sleep. Each part was scored (range: 0-3; higher scores indicating worse sleep). A total global PSQI was derived by summing the seven components (range: 0 to 21; higher scores indicating poor sleep quality). A global PSQI score $>5$ yielded a diagnostic sensitivity of $89 \%$ and specificity of $86.5 \%(\mathrm{~K}=$ $0.75, p \leq 0.001)$ in distinguishing "good" from "poor" sleepers. "Good sleep" was defined as global PSQI scores of 0-5 and "poor sleep" was global PSQI scores of 6-12 (Buysse et al. 1989). The tool was validated in Ethiopia among community dwellers having Cronbach's alpha of 0.59 , sensitivity of $82 \%$, and specificity of $56.2 \%$ (Salahuddin et al. 2017).

Hospital anxiety and depression scale (HADS) were used to assess anxiety and depression. The tool has anxiety subscale (HADS-A) and the depression subscale (HADS-D). It has a cutoff point $\geq 8$ for each subscale (Salahuddin et al. 2017). HADS had an internal consistency of 0.78 for the anxiety, 0.76 for depression subscales and 0.87 for the full scale in a validation study conducted among HIV Infected Patients in Ethiopia (Reda 2011a). HIV/AIDS related stigma scale was used to assess stigma. It is a 12-item screening tool developed by Annelies Van Rie, Sohini Sengupta. The tool has 4point Likert response. Each items were scored with 0 (strongly disagree) and 3 (strongly agree). Participants who scored above the mean score were considered as stigmatized (Reda 2011b; Van Rie et al. 2008). The scale demonstrated acceptable internal consistency (Cronbach's alpha $=0.73$ ) in a study conducted in Uganda (Tsai et al. 2013).

Sleep hygiene index (SHI), a 13-item self-report measure designed to assess the practice of sleep hygiene behaviors. Each item is rated on a five-point scale ranging from 0 (never) to 4 (always). Total scores range from 0 to 52 with a higher score representing poor sleep hygiene (Cho et al. 2013). Oslo Social Support Scale (OSS) was used to assess respondents support system which is a 3 items measure of support with internal consistency (Cronbach's $\alpha=0.50$ ) (Dalgard 2009).

\section{Data quality control issues}

Training was given to the data collectors and supervisors on the data collection tool and sampling techniques. Supervision was held regularly during the data collection period both by the researcher, co-investigators and supervisors to check on a daily basis for completeness and consistency.

\section{Analysis}

Data were analyzed using SPSS version 20. Description statistics (frequencies, proportions, means, and standard deviations) were used to present the sociodemographic characteristics and the prevalence of sleep quality. Both bivariate and multivariate logistic regression analysis were carried out to see the association of each independent variable with the outcome variable. A $p$-value of less than 0.05 was considered statistically significant, and an adjusted odds ratio with $95 \% \mathrm{CI}$ was calculated to determine the association.

\section{Ethical considerations}

Ethical clearance was obtained from the joint ethics committee of the University of Gondar and Amanuel Mental Specialized Hospital and Addis Ababa health bureau based upon Declaration of Helsinki (DoH). The data collectors clearly explained the purpose and importance of the study to each study participant before they proceed into actual activities. Information was collected after obtaining written consent from each participant. Written informed consent was obtained from the study participants and comparison of study participants after oral information about the study, including an assurance that they could withdraw from the study at any time. Confidentiality was maintained by anonymous questionnaire.

\section{Results}

A total of 396 study participants were interviewed, giving a response rate of $97.1 \%$. The mean age of the respondents was 38.6 years with SD $( \pm 10.8)$. The proportion of male to female participants was almost equal (50.3 to 49.7\%). More than half of the client's $(n=276,69.7 \%)$ were Orthodox by religion and most of the respondents were married $(n=208,52.5 \%)$ and regarding the education level of the respondents 176(44.4\%) had attended secondary school (Table 1). 
HIV related clinical characteristics of the participants Among the study participants, the majority ( $n=294$, $74.2 \%)$ was on clinical stage I, 219 (55.3\%) had greater than 200 cells $/ \mathrm{mm}^{3}$ of $\mathrm{CD}_{4}$ count, $296(74.7 \%)$ on the first line regimen of ART drugs and 272 (68.7\%) had duration of HIV/AIDS diagnosis greater than 10 years (Table 2).

\section{Psycho-social characteristics of the participants}

Regarding to psycho-social characteristics, more than half $(51.5 \%)$ were in high depression severity, 109 (27.5\%) of the participants had general anxiety disorder symptoms, 194(49.0\%) of them were stigmatized and $164(41.4 \%)$ had poor social support. Among one hundred ninety seven female participants 117 (59.4\%) and of one hundred ninety nine male participants 87 (43.7\%) had depression symptoms.

\section{Substance use by participants}

Two hundred six (52.0\%) the study participants were current substances users. Of them, majority $(n=183$, $46.2 \%)$ use alcohol followed by $(n=109,27.5 \%)$ use tobacco (Fig. 1).

Table 1 Socio demographic characteristics of people living with HIV/AIDS on follow-up at Zewditu Memorial Hospital, Ethiopia, 2018. $(n=396)$

\begin{tabular}{|c|c|c|c|}
\hline Variable & Category & Frequency & $M(S D)$ or $\%$ \\
\hline Age (mean and SD) & & & $38.57 \pm 10.76$ \\
\hline \multirow[t]{2}{*}{ Sex } & Male & 199 & 50.3 \\
\hline & Female & 197 & 49.7 \\
\hline \multirow[t]{4}{*}{ Religion } & Orthodox & 265 & 66.9 \\
\hline & Muslim & 24 & 6.1 \\
\hline & Protestant & 84 & 21.2 \\
\hline & Others $^{a}$ & 23 & 5.8 \\
\hline \multirow[t]{3}{*}{ Marital status } & Single & 166 & 41.9 \\
\hline & Married & 208 & 52.5 \\
\hline & Others ${ }^{b}$ & 22 & 5.6 \\
\hline \multirow[t]{4}{*}{ Educational status } & Can't write and read & 20 & 5.1 \\
\hline & Primary & 88 & 22.2 \\
\hline & Secondary & 176 & 44.4 \\
\hline & Tertiary and above & 112 & 28.3 \\
\hline \multirow[t]{4}{*}{ Occupational status } & Employed & 154 & 38.8 \\
\hline & Private business & 150 & 37.9 \\
\hline & Students & 66 & 16.7 \\
\hline & Others $^{c}$ & 26 & 6.6 \\
\hline \multirow[t]{3}{*}{ Living arrangement } & with family & 244 & 61.6 \\
\hline & alone & 133 & 33.6 \\
\hline & Others $^{d}$ & 19 & 4.8 \\
\hline
\end{tabular}

N.B. ${ }^{\text {a }}$ Catholic, Wakifeta ${ }^{\mathrm{b}}$ Separated, Divorced, widowed ${ }^{\mathrm{C}}$ Daily laborer, House wife, Farmer ${ }^{d}$ with relatives, Adopted

\section{Poor sleep quality and factors associated among people} with HIV/AIDS

The magnitude of poor sleep quality among people living with HIV/AIDS was found to be 55.6\%. Multivariable logistic regression revealed female sex, depression, CD4 less than 200 cells $/ \mathrm{mm}^{3}$ count, duration of HIV/AIDS diagnosis, current use of tobacco, current use of chat or caffeinated drinks and poor sleep hygiene were significantly associated with poor sleep quality.

The magnitude of poor sleep quality was found to be more than 3 times higher in females compared to males [AOR $=3.40,95 \% \mathrm{CI}:(1.80,6.41)]$. The odds of having poor sleep quality among depressed respondents were 3.52 times higher as compared to non-depressed respondents $[$ AOR $=3.52$, 95\% CI: $(1.95,6.32)]$. The odds of experiencing poor sleep quality among Participants with shorter duration of HIV diagnosis were more than three times as compared to those who had longer duration of diagnosis $[\mathrm{AOR}=3.43,95 \% \mathrm{CI}$ : $(1.61,7.29)]$. Similarly, Individuals whose $\mathrm{CD}_{4}$ count were less than 200cells $/ \mathrm{mm}^{3}$ were 3.18 times more likely to have poor sleep quality than individuals with $\mathrm{CD}_{4}$ counts greater than 200cells/ $\mathrm{mm}^{3}[\mathrm{AOR}=3.18,95 \% \mathrm{CI}:(1.65,6.13)]$. Regarding substances, those who smoke cigarette currently had 5.69 times more likely to have poor sleep quality as compared with non-smokers $[\mathrm{AOR}=5.69,95 \% \mathrm{CI}$ : $(2.04,15.9)]$. In addition, those taking chat or caffeinated drinks were 2.65 times higher to have poor sleep quality as compared to those who didn't use [AOR $=2.65,95 \% \mathrm{CI}$ : $(1.06,6.64)]$. Finally, The odds of poor sleeps quality was 3.55 times higher among participants with poor sleep hygiene as compared to those with good sleep hygiene [(AOR = 3.55, 95\%CI: $(1.85,6.78)]$ (Table 3).

\section{Discussion}

This study was a first attempt to ascertain the magnitude of sleep quality and its possible association with various variables among people living with HIV/AIDS in Ethiopia. The results from the current survey revealed that a remarkable proportion of people living with HIV/ AIDS had experienced poor sleep quality. More than half of the people living with HIV/AIDS (55.6\%) experienced poor sleep quality. The magnitude of this study is in line with the studies conducted in Nigeria (59.3\%), South Africa (55.8\%), Indonesia (52\%) and Mexico (58.6\%) (Ferreira and Ceolim 2012; Oshinaike et al. 2014; Buysse et al. 1989; Salahuddin et al. 2017).

Contrarily, the magnitude of poor sleep quality in this study was higher than study results in Brazil (46.7\%) (Rodríguez-Estrada et al. 2018a), Iran (47.5\%) (Reda 2011a), China (43.1\%) (Huang et al. 2017), Romania (42\%) (Reda 2011b), Spain (40.9\%) (Van Rie et al. 2008), France (47\%) (Allavena et al. 2016) and USA (26\%) (Tsai et al. 2013). Furthermore the current finding is lower 
Table 2 HIV related clinical characteristics of people living with HIV/AIDS on follow up at Zewditu Memorial Hospital, Addis Ababa, Ethiopia, 2018. $(n=396)$

\begin{tabular}{|c|c|c|c|}
\hline Variable & Category & Frequency(396) & Percentage (\%) \\
\hline \multirow[t]{4}{*}{ WHO clinical stage } & stage I & 294 & 74.2 \\
\hline & stage \| & 59 & 14.9 \\
\hline & stage III & 35 & 8.8 \\
\hline & stage IV & 8 & 2.0 \\
\hline \multirow[t]{2}{*}{$\mathrm{CD}_{4}$ count } & $\leq 200$ cells $/ \mathrm{mm}^{3}$ & 177 & 44.7 \\
\hline & $>200$ cells $/ \mathrm{mm}^{3}$ & 219 & 55.3 \\
\hline \multirow[t]{2}{*}{ Duration of HIV/AIDS diagnosis } & $\leq 10$ years & 124 & 31.3 \\
\hline & $>10$ years & 272 & 68.7 \\
\hline \multirow[t]{2}{*}{ ART type } & first line regimen & 296 & 74.7 \\
\hline & Second line regimen & 100 & 25.3 \\
\hline \multirow[t]{2}{*}{ Co-morbid chronic medical illness } & No & 255 & 64.4 \\
\hline & Yes & 141 & 35.6 \\
\hline \multirow[t]{4}{*}{ Types of chronic medical conditions } & Hypertension & 47 & 33.4 \\
\hline & Diabetes mellitus & 41 & 29.0 \\
\hline & Tuberculosis & 35 & 24.8 \\
\hline & Others & 18 & 12.7 \\
\hline
\end{tabular}

than the study conducted in USA 66.7\% (Cho et al. 2013). The possible reason for the observed variation might be the difference in socio-cultural conditions, in methodological designs and difference in hospital setting and caring modality.

In this study, poor sleep quality was significantly associated with female gender among people with HIV/
AIDS. This could be due to the fact that females are more prone to stress due to the burden of excessive household responsibilities and changes in hormonal level. This result is supported by a study carried out in Nigeria (Oshinaike et al. 2014).

The current study also found that depressed respondents were significantly associated with poor sleep

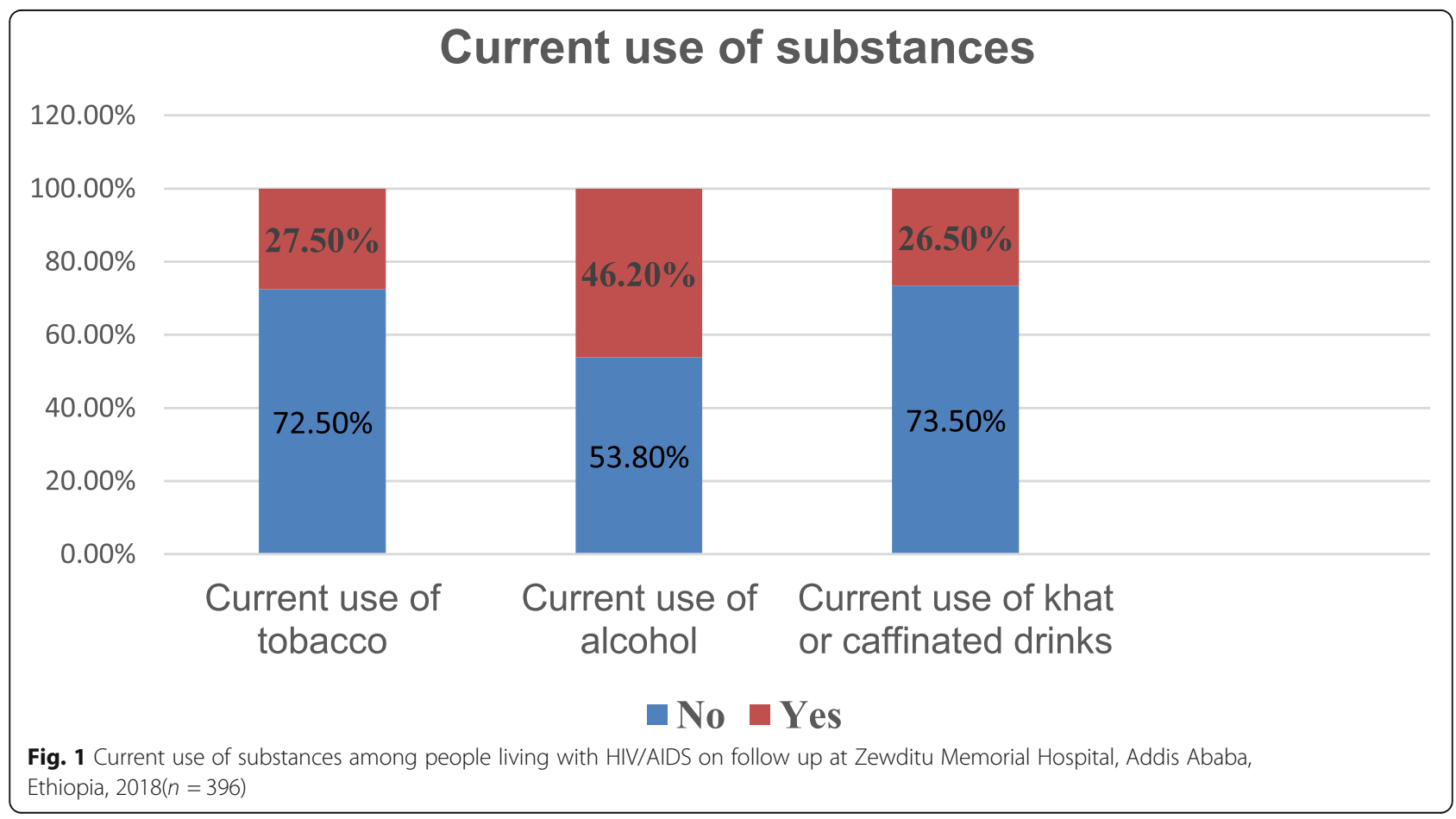


Table 3 Factors associated with poor sleep quality among people living with HIV/AIDS at Zewditu Memorial Hospital (Bivariate and multivariate analysis) $(n=396)$, Addis Ababa, Ethiopia, 2018

\begin{tabular}{|c|c|c|c|c|c|}
\hline \multirow[t]{2}{*}{ Variables } & \multirow[t]{2}{*}{ Categories } & \multicolumn{2}{|c|}{ sleep quality } & \multirow[t]{2}{*}{$\operatorname{COR}(95 \% \mathrm{Cl})$} & \multirow[t]{2}{*}{$\operatorname{AOR}(95 \% \mathrm{Cl})$} \\
\hline & & Poor & Good & & \\
\hline$\overline{\text { Age }}$ & & & & $0.98(0.96,1.00)$ & $0.98(0.95,1.01)$ \\
\hline \multirow[t]{2}{*}{ Sex } & Male & 75 & 124 & 1.00 & 1.00 \\
\hline & Female & 145 & 52 & $4.61(3.00,7.06)$ & $3.40(1.80,6.41) * *$ \\
\hline \multirow[t]{2}{*}{ Depression } & No & 72 & 120 & 1.00 & 1.00 \\
\hline & Yes & 148 & 56 & $4.40(2.88,6.73)$ & $3.52(1.95,6.32)^{* *}$ \\
\hline \multirow[t]{2}{*}{ Anxiety } & No & 153 & 134 & 1.00 & 1.00 \\
\hline & Yes & 67 & 42 & $1.39(0.89,2.19)$ & $0.92(0.48,176)$ \\
\hline \multirow[t]{2}{*}{ Perceived stigma } & No & 78 & 124 & 1.00 & 1.00 \\
\hline & Yes & 142 & 52 & $4.34(2.83,6.64)$ & $0.82(0.39,1.76)$ \\
\hline \multirow[t]{3}{*}{ Social support } & Poor & 128 & 36 & $7.11(3.51,14.3)$ & $2.48(0.91,6.75)$ \\
\hline & Moderate & 76 & 108 & $1.40(0.72,2.74)$ & $1.20(0.50,2.88)$ \\
\hline & Strong & 16 & 32 & 1.00 & 1.00 \\
\hline \multirow[t]{2}{*}{$\mathrm{CD}_{4}$ count } & $>200$ cells $/ \mathrm{mm}^{3}$ & 79 & 140 & 1.00 & 1.00 \\
\hline & $\leq 200$ cells $/ \mathrm{mm}^{3}$ & 141 & 36 & $6.94(4.38,10.9)$ & $3.18(1.65,6.13) * *$ \\
\hline \multirow[t]{2}{*}{ Duration HIV diagnosis } & $>10$ years & 115 & 157 & 1.00 & 1.00 \\
\hline & $\leq 10$ years & 105 & 19 & $7.54(4.37,13.0)$ & $3.43(1.61,7.29) * *$ \\
\hline \multirow[t]{2}{*}{ Co-morbid medical illness } & No & 111 & 144 & 1.00 & 1.00 \\
\hline & Yes & 109 & 32 & $4.41(2.77,7.03)$ & $0.67(0.28,1.62)$ \\
\hline \multirow[t]{2}{*}{ Current use of tobacco } & No & 123 & 164 & 1.00 & 1.00 \\
\hline & Yes & 97 & 12 & $10.7(5.66,20.5)$ & $5.69(2.04,15.9) * *$ \\
\hline \multirow[t]{2}{*}{ Current use of alcohol } & No & 84 & 129 & 1.00 & 1.00 \\
\hline & Yes & 136 & 47 & $4.44(2.88,6.83)$ & $0.94(0.43,2.05)$ \\
\hline \multirow[t]{2}{*}{ Current use of chat or caffeinated drinks } & No & 140 & 166 & 1.00 & 1.00 \\
\hline & Yes & 80 & 10 & $9.48(4.73,19.0)$ & $2.65(1.06,6.64) *$ \\
\hline \multirow[t]{2}{*}{ Sleep hygiene } & Good & 84 & 109 & 1.00 & 1.00 \\
\hline & Poor & 136 & 67 & $2.64(1.75,3.96)$ & $3.55(1.85,6.78) * *$ \\
\hline
\end{tabular}

N.B. 1.00 references $*$-value less than $0.05 * p$-value less than 0.01

quality as compared with non-depressed respondents. This may be due to depressed individuals have decreased serotonin neurotransmitters that results in diminished cognitive performance affects normal sleep pattern. This finding is in agreement with studies done in China (Huang et al. 2017), Europe and USA (Allavena et al. 2016; Rodríguez-Estrada et al. 2018b; Redman n.d.; Dabaghzadeh et al. 2013; Arbune et al. 2017). Similarly different studies supported that poor emotion regulation modifies the point and prospective relationship between sleep quality and depression symptom (O'Leary et al. 2017; Pillai et al. 2011; Zhai et al. 2015).

$\mathrm{CD}_{4}$ count less than 200cells $/ \mathrm{mm}^{3}$ were a significant factor to develop poor sleep quality among people with HIV/AIDS. Probably, immune system is directly linked to the brain by a complex network of nerves, hormones, and neuropeptides. This network of specific physiological pathways is the primary determinant of neuropathology to have a direct impact on health including sleep. The finding of this study coincides with a study done in Nigeria (Bisong 2017; Oshinaike et al. 2014) and Mexico (Rodríguez-Estrada et al. 2018b).

Similarly, shorter duration of HIV diagnosis were significantly associated with poor sleep quality as compared longer duration of diagnosis. The possible reasoning might be HIV-positive patients feel stigmatized and this may contribute to frequent psychological stress and emotional disturbances. The result is supported by research conducted in Nigeria (Oshinaike et al. 2014).

Furthermore, use of substances within the current 3 months (i.e. tobacco, chat or caffeinated drinks) were significantly associated with poor sleep quality. The possible reasons behind these is biological effect of the substances on the brain results in disturbance of circadian 
rhythms which is associated with symptoms of poor sleep quality. This finding agrees with a study conducted in France (Allavena et al. 2016), US geographic areas (Crum-Cianflone et al. 2012; Ramamoorthy et al. 2017) and studies conducted in Ethiopia at community level (Manzar et al. 2017; Berhanu et al. 2018).

Finally, in the present study there is a strong relationship between poor sleep hygiene and poor sleep quality. Even if, the finding of this study has no corresponding literature among the same population, it's supported by study undertaken in India to identify the relationship between sleep hygiene practices and sleep quality among cancer patients (Roselin and Rhenius 2018). The current study implicates that health care providers must give attention to the sleep conditions of people with HIV/AIDs which have an enormous impact on treatment adherence and risk of psychological problem development.

\section{Limitation of the study}

The current study was limited to assess chronic insomnia having a duration of 6 months due to the nature of the assessment tool used and missed participants who might experience more sleep disturbances (i.e. participants with severe mental illness and acute physical illness) due to the exclusion criteria set. Hence, future studies focused on casual relations are of great significance.

\section{Conclusion}

In summary, this study revealed that more than half of people living with HIV/AIDS were found to have poor sleep quality. Being female, depression symptoms, lower CD4 count, shorter duration of HIV/AIDS diagnosis, current use of tobacco, chat or caffeinated drinks, and poor sleep hygiene were factors significantly associated with poor sleep quality. The findings suggest that routine screening of sleep disturbances among people living with HIV/AIDS is highly recommended. An intervention targeted the factors influencing sleep quality is also suggested.

\section{Abbreviations}

AOR: Adjusted odd ratio; Cl: Confidence interval; PSQI: Pittsburgh Sleep Quality Index

\section{Acknowledgements}

We would like to thank Amanual Mental Specialized Hospital, University of Gondar and Zewditu Memorial Hospital staffs for their support and assistance throughout the study process.

\section{Authors' contributions}

Nebiyu Mengistu (nebiyumen@gmail.com) organized the original investigation; coordinated the collection of data; analysis and writing report. Telake Azale (atelake07@gmail.com), Mahlet Fikreyesus (mahifyf@gmail.com) and Elsa Melaku (elsa_mlk@yahoo.com) equally contributed to the design of the study, performed the statistical analyses, Solomon Yimer (sopsycha@gmail.com) and Seid Shumye (Seidshumye22@gmail.com) contributed to the statistical analyses, drafted the manuscript and revision of the Manuscript. The authors read and approved the final manuscript.

\section{Funding}

The sources of funding for the current research is from Amanuel Mental specialized Hospital. The funding organization did not have any role in the design of the study, collection, analysis, interpretation of data and in writing the manuscript.

\section{Availability of data and materials}

All data generated or analyzed during this study are included in this published article. The data sets of the current study is available from [Nebiyu Mengistu, email: nebiyumen@gmail.com; Mobile: + 251931333504, Dilla university, Dilla] upon reasonable request.

\section{Ethics approval and consent to participate}

Ethical approval was obtained from joint Ethical Review Committee of University of Gondar and Amanual Mental Specialized Hospital (No Committee reference number). Written consent was taken from the participants for their voluntary participation. Confidentiality was maintained throughout the study process.

\section{Consent for publication}

N/A

\section{Competing interests}

We declare that there is no any financial or non-financial conflict of interest.

\section{Author details}

${ }^{1}$ Department of Psychiatry, Dilla University, P.O.Box (DU): 419, Dilla, Ethiopia. ${ }^{2}$ Gondar University, P.O. Box (GU): 196, Gondar, Ethiopia. ${ }^{3}$ Amanuel Mental Specialized Hospital, P.O. Box: 1971, Addis Ababa, Ethiopia.

Received: 6 May 2020 Accepted: 9 December 2020

Published online: 04 January 2021

\section{References}

Allavena C, Guimard T, Billaud E, De la Tullaye S, Reliquet V, Pineau S, et al. Prevalence and risk factors of sleep disturbance in a large HIV-infected adult population. AIDS Behav. 2016;20(2):339-44.

Arbune M, Dumitru I-M, Cretu-Stuparu M. Characteristics of sleep disorders in Romanian adults infected with human immunodeficiency virus. ARS Medica Tomitana. 2017;23(3):126-31.

Association AP. Diagnostic and statistical manual of mental disorders (DSM-5 ${ }^{\circledR}$ ): American Psychiatric Pub; 2013.

Azagew AW, Woreta HK, Tilahun AD, Anlay DZ. High prevalence of pain among adult HIV-infected patients at University of Gondar Hospital, Northwest Ethiopia. J Pain Res. 2017;10:2461.

Babson KA, Heinz AJ, Bonn-Miller MO. HIV medication adherence and HIV symptom severity: the roles of sleep quality and memory. AIDS Patient Care STDS. 2013;27(10):544-52.

Barlow DH. Clinical handbook of psychological disorders: a step-by-step treatment manual: Guilford publications; 2014.

Berhanu H, Mossie A, Tadesse S, Geleta D. Prevalence and associated factors of sleep quality among adults in Jimma town, Southwest Ethiopia: a community-based cross-sectional study. Sleep Disord. 2018;2018:1-10.

Bisong E. Predictors of sleep disorders among HIV out-patients in a tertiary hospital. Recent Adv Biol Med. 2017:3(2017):2747.

Buysse DJ, Reynolds CF, Monk TH, Berman SR, Kupfer DJ. The Pittsburgh sleep quality index: a new instrument for psychiatric practice and research. Psychiatry Res. 1989;28(2):193-213.

Cho S, Kim G-S, Lee J-H. Psychometric evaluation of the sleep hygiene index: a sample of patients with chronic pain. Health Qual Life Outcomes. 2013;11(1): 213.

Crum-Cianflone NF, Roediger MP, Moore DJ, Hale B, Weintrob A, Ganesan A, et al. Prevalence and factors associated with sleep disturbances among earlytreated HIV-infected persons. Clin Infect Dis. 2012;54(10):1485-94.

Dabaghzadeh F, Khalili H, Ghaeli P, Alimadadi A. Sleep quality and its correlates in HIV positive patients who are candidates for initiation of antiretroviral therapy. Iran J Psychiatry. 2013;8(4):160. 
Dalgard O. Social support-consequences for individual and society. EUPHIX EUphact Bilthoven: RIVM http://www.euphix.org. EUphact\Determinants.of. health\Environment\Socialsupport. 2009;16.

Ferreira LTK, Ceolim MF. Sleep quality in HIV-positive outpatients. Rev Esc Enferm USP. 2012;46(4):892-99. https://doi.org/10.1590/s0080-62342012000400016.

Gamaldo CE, Gamaldo A, Creighton J, Salas RE, Selnes OA, David PM, et al. Evaluating sleep and cognition in HIV. J Acquir Immune Defic Syndr (1999). 2013;63(5)609-16. https://doi.org/10.1097/QAl.0b013e31829d63ab.

Huang X, Li H, Meyers K, Xia W, Meng Z, Li C, et al. Burden of sleep disturbances and associated risk factors: a cross-sectional survey among HIV-infected persons on antiretroviral therapy across China. Sci Rep. 2017;7(1):3657.

Hudson A, Kirksey K, Holzemer W. The influence of symptoms on quality of life among HIV-infected women. West J Nurs Res. 2004;26(1):9-23.

Johnston L, O'Malley P, Bachman J, Schulenberg J, Patrick M, Miech R. HIV/AIDS: risk \& protective behaviors among adults ages 21 to 40 in the US, 20042016; 2017

Junqueira P, Bellucci S, Rossini S, Reimão R. Women living with HIV/AIDS: sleep impairment, anxiety and depression symptoms. Arq Neuropsiquiatr. 2008; 66(4):817-20.

Manzar MD, Salahuddin M, Maru TT, Dadi TL, Abiche MG, Abateneh DD, et al. Sleep correlates of substance use in community-dwelling Ethiopian adults. Sleep Breath. 2017;21(4):1005-11.

McGrath L, Reid S. Sleep and Quality of Life in HIV and AIDS. In: Verster J.C., Pandi-Perumal S.R., Streiner D.L. (eds) Sleep and Quality of Life in Clinical Medicine. Humana Press; 2018:505-14. https://doi.org/10.1007/978-1-60327343-5_53.

O'Leary K, Bylsma LM, Rottenberg J. Why might poor sleep quality lead to depression? A role for emotion regulation. Cognit Emot. 2017;31(8):1698-706.

Oshinaike O, Akinbami A, Ojelabi O, Dada A, Dosunmu A, John Olabode S. Quality of sleep in an HIV population on antiretroviral therapy at an urban tertiary Centre in Lagos, Nigeria. Neurol Res Int. 2014;2014:6. https://doi.org/ 10.1155/2014/298703

Pillai V, Kalmbach DA, Ciesla JA. A meta-analysis of electroencephalographic sleep in depression: evidence for genetic biomarkers. Biol Psychiatry. 2011;70(10): 912-9.

Qaseem A, Kansagara D, Forciea MA, Cooke M, Denberg TD. Management of chronic insomnia disorder in adults: a clinical practice guideline from the American College of Physicians. Ann Intern Med. 2016;165(2):125-33.

Ramamoorthy V, Campa A, Rubens M, Martinez SS, Fleetwood C, Stewart T, et al. Caffeine and insomnia in people living with HIV from the Miami adult studies on HIV (MASH) cohort. J Assoc Nurses AIDS Care. 2017;28(6):897-906.

Reda AA. Reliability and validity of the Ethiopian version of the hospital anxiety and depression scale (HADS) in HIV infected patients. PLoS One. 2011a;6(1): e16049.

Redman, K. Sleep quality and immune changes in HIV positive people in the first six months of starting highly active antiretroviral therapy (HAART); 2016.

Reid S, Dwyer J. Insomnia in HIV infection: a systematic review of prevalence, correlates, and management. Psychosom Med. 2005;67(2):260-9.

Rodríguez-Estrada E, Iglesias-Chiesa M, Fresán-Orellana A, Reyes-Terán G. Factors associated with poor sleep quality among HIV-positive individuals in Mexico City. Salud Mental. 2018b;41(3):123-9.

Roselin V, Rhenius JA. Relationship of sleep hygiene practices and sleep quality among cancer patients. IOSR J Nurs Health Sci (IOSR-JNHS). 2018;7(Issue 1 Ver. II):2320-1940.

Rubinstein ML, Selwyn PA. High prevalence of insomnia in an outpatient population with HIV infection. J Acquir Immune Defic Syndr Hum Retrovirol. 1998;19:260-5.

Saberi P, Neilands TB, Johnson MO. Quality of sleep: associations with antiretroviral nonadherence. AIDS Patient Care STDS. 2011;25(9):517-24

Salahuddin M, Maru TT, Kumalo A, Pandi-Perumal SR, Bahammam AS, Manzar MD. Validation of the Pittsburgh sleep quality index in community dwelling Ethiopian adults. Health Qual Life Outcomes. 2017;15(1):58.

Taibi DM. Sleep disturbances in persons living with HIV. J Assoc Nurses AIDS Care. 2013;24(1):S72-85

Tsai AC, Weiser SD, Steward WT, Mukiibi NF, Kawuma A, Kembabazi A, et al. Evidence for the reliability and validity of the internalized AIDS-related stigma scale in rural Uganda. AIDS Behav. 2013;17(1):427-33.

Van Rie A, Sengupta S, Pungrassami P, Balthip Q, Choonuan S, Kasetjaroen Y, et al. Measuring stigma associated with tuberculosis and HIV/AIDS in southern Thailand: exploratory and confirmatory factor analyses of two new scales. Trop Med Int Health. 2008;13(1):21-30.
Zhai L, Zhang H, Zhang D. Sleep duration and depression among adults: a metaanalysis of prospective studies. Depress Anxiety. 2015;32(9):664-70.

\section{Publisher's Note}

Springer Nature remains neutral with regard to jurisdictional claims in published maps and institutional affiliations.
Ready to submit your research? Choose BMC and benefit from:

- fast, convenient online submission

- thorough peer review by experienced researchers in your field

- rapid publication on acceptance

- support for research data, including large and complex data types

- gold Open Access which fosters wider collaboration and increased citations

- maximum visibility for your research: over $100 \mathrm{M}$ website views per year

At BMC, research is always in progress.

Learn more biomedcentral.com/submissions 